\title{
Concepts in diagnosing, scoring, and monitoring tenosynovitis and other tendon abnormalities in patients with rheumatoid arthritis - the role of musculoskeletal ultrasound.
}

\author{
Mihaela C. Micu', Florian Berghea², Daniela Fodor ${ }^{3}$
}

${ }^{1}$ Rheumatology Division, Rehabilitation Clinical Hospital, Cluj-Napoca, ${ }^{2}$ Clinical Hospital Sf. Maria, Bucuresti, ${ }^{3} 2^{\text {nd }}$ Internal Medicine Department, "Iuliu Hatieganu" University of Medicine and Pharmacy, Cluj-Napoca, Romania

\begin{abstract}
In the last years, important advancements have been made in implementing high resolution imaging related information inside the global management algorithm in RA patients. Musculoskeletal ultrasound has already proven its utility in visualizing directly the joint synovial tissue, the synovial vascularization and in monitoring the response to therapy. Recently, much attention has been given to the presence of tenosynovitis, as a constant, complementary but different facet of the inflammatory involvement in RA. Tenosynovitis identification in early RA stages may allow adequate treatment adjustment in early and established disease in order to prevent and/ or slow down the development of structural damage at tendon and joint level.

Keywords: tenosynovitis, ultrasound, rheumatoid arthritis
\end{abstract}

\section{Introduction}

Rheumatoid arthritis (RA) management should focus on inflammation suppression, therefore, limiting as much as possible the disease damage progression at joint and peri-articular level. Achievement and maintenance of a good quality of life during the disease course is tightly linked to an early, accurate diagnosis and to a tailored treatment commencement and adjustment, aiming at sustained remission [1-4]. In this regard, it is of the utmost importance to perform an accurate baseline disease activity and follow-up outcome assessment [5].

However, the presence of subclinical residual inflammatory joint activity with subsequent documented radiological progression in more than $25 \%$ of patients attaining clinical remission, has triggered attention for complementary evaluation methods [6-17].

Received 02.06.2016 Accepted 20.06.2016

Med Ultrason

2016, Vol. 18, No 3, 370-377

Corresponding author: Florian Berghea

Clinical Hospital Sf. Maria

37-39 Ion Mihalache Bd

Bucharest, Romania

Fax: +040212223555

E-mail: berghea1@gmail.com
Lately, important advancements have been made in implementing high resolution imaging related information inside the global management algorithm in RA patients [6-9]. Currently, available evidence supports the important contribution of several high resolution imaging methods in identifying joint, peri-articular, and erosive changes at any point during the disease course. Musculoskeletal ultrasound (MSUS) has already proven its utility for directly visualization of the joint synovial tissue (morphology and quantification), the synovial vascularization (presence and quantification), and in monitoring the response to therapy [18-27]. Recently, much attention has been given to the presence of tenosynovitis, as a constant, complementary, but different facet of the inflammatory involvement in RA [28-30]. In this scenario, identification of tenosynovitis in early RA stages along with treatment monitoring in early and established disease should not only help in improving the new classification criteria but also in preventing or slowing down the development of structural damage at tendon and joint level [31-34].

\section{Clinical and imaging evaluation}

The first descriptions regarding the presence of tenosynovitis as a clinical finding in early RA (ERA) are 
present in the literature since 1957. Jacobs et al reported three cases of patients with RA onset where tenosynovitis was the primary manifestation. The authors underlined the fact that tenosynovitis may occur as isolated attacks at the disease onset and should not be overlooked [35]. In fact, tenosynovitis is frequently overlooked in clinical practice because clinical examination (CE) might be very challenging in patients with multiple inflammatory and structural joint and peri-articular pathology, occurring in complex anatomical areas such as the hand or foot. Indeed, conventional radiology does not offer satisfactory information about the soft tissues. Therefore, high resolution imaging methods such as magnetic resonance imaging (MRI) and MSUS are extremely useful since clinical and subclinical joint and periarticular involvement is accurately detected [29-32].

The new ACR/ EULAR classification criteria for RA were developed in order to identify individuals at high risk of persistent and destructive disease, who might benefit from disease-modifying therapy. However, these criteria are not perfect since only the presence of synovitis, erosions and laboratory parameters are included.

Cader et al highlighted in a paper published in 2011 that the new ACR/ EULAR classification criteria for RA may still lead to significant over - and under - diagnosis within the first months after symptom onset and may overlook patients with symmetrical seronegative arthritis and limited joint involvement. Therefore, identification of additional, more sensitive and specific tests/ imaging information for very early detection of RA is needed in the field of rheumatology [36].

However, the EULAR recommendations for the use of imaging of the joints in the clinical management of RA are focusing strictly on the early articular evaluation using MRI or MSUS without taking into consideration a possible peri-articular involvement [9]. On the other hand, the ACR report on reasonable use of MSUS in rheumatology clinical practice mention the fact that "For a patient with peri-articular pain without definitive diagnosis on clinical examination, it is reasonable to use MSUS to evaluate tendon and soft tissue pathologies and the nature and localization of adjacent swelling at the shoulder, elbow, hand, hip, knee, ankle, and forefoot" [7].

In the last 10 years, several papers have drawn attention to tenosynovitis as a phenomenon present from the early stages of the disease, evolving in parallel with joint inflammation. Mc Queen et al report tenosynovitis in the dominant wrist, especially in the first year of disease, to be a frequent finding found at MRI examinations [37]. Indeed, another MRI based longitudinal study conducted by Lindegaard et al concluded that tenosynovitis in the dominant wrist and at MCF level was present in about 60
$\%$ of the ERA patients at baseline with reduction to $28 \%$ after 6 months and a yearfollow- up, showing a good response to therapy superior to the synovitis response [38].

Wakefield et al reinforced the idea in a paper published in 2007, a paper in which the frequency and distribution of finger tenosynovitis in non-treated ERA patients was studied using two imaging methods: MSUS and MRI. The authors identified 28\%/ $64 \%$ flexor tenosynovitis and $14 \% / 40 \%$ extensors tenosynovitis on MSUS vs MRI. No controls showed imaging tenosynovitis [29]. In patients with undifferentiated arthritis or patients with clinically suspected RA at the time of presentation, who had no typical findings of RA on conventional radiographs, Eshed et al found a statistic significant difference when analyzing tenosynovitis between RA and non-RA patients. The ratio flexor/ extensor tenosynovitis was $60 \% / 14 \%$ in RA patients compared to only $24 \%$ / $12 \%$ in non- RA patients, pointing out the importance of tenosynovitis of the flexor tendons for the early stages of the disease for the diagnostic of RA. This parameter was the strongest early predictor of RA compared to other imaging parameters. When ACR criteria were added to the logistic regression analysis, only the presence of the rheumatoid factor (RF) was stronger than tenosynovitis of the flexor tendons for the prediction of RA [39].

Furthermore, other recent studies evaluated the presence of wrist tenosynovitis (especially of the extensor carpi ulnaris and flexor tendons) in early and very early disease stages (VERA) and showed that its presence was most significantly associated with progression to RA. Tenosynovitis was proved to be an additional parameter that should be separately monitored. Its presence is linked to the improvement of the diagnostic capacity (sensitivity) of the new classification criteria $[31,32,40]$. Of note, Navalho et al identified MRI tenosynovitis as a discriminating factor of the evolution toward RA in patients with VERA (onset $<3$ months). Extensor carpi ulnaris (EUC) and flexors of the second finger tenosynovitis in addition to radio-carpal joint synovitis were recognized as significantly associated with progression to RA. Tenosynovitis of the flexor tendons of the second finger remained a discriminating feature even in patients with longer disease duration [32].

MSUS is a very useful imaging tool for baseline assessment and further monitoring since it is non-radiating and more sensitive in detecting clinical and subclinical synovitis and tenosynovitis in comparison to $\mathrm{CE}$ in RA target areas [30,40-44]. Moreover, MSUS has been considered by some authors as the "goldstandard" method for the evaluation of superficial tendons [45]. In comparison to MRI it permits not only multi-planar evaluation but also real time dynamic assessment and vasculariza- 
tion detection [42,46-54]. MSUS evaluation can be repeated anytime during the disease course, offering a key to a better understanding and monitoring in early stages and longstanding disease. In fact, MSUS creates the possibility to analyze better the transition between inflammatory tendon pathology to partial or total damage.

\section{OMERACT filter - validity, reliability, responsiveness and feasibility. Scoring systems.}

A lot of effort has been made in the last years to develop a common language between different evaluators and centers. This process requires the elaboration of better US definitions, a better image acquisition standardization and the improvement of the inter-observer reliability parameters for inflammatory as well as for tendon damage lesions. The final goal would be to implement the tendons MSUS evaluation in clinical practice as well as in clinical trials.

The Outcome Measures in Rheumatology (OMERACT) Ultrasound group published definitions for tenosynovitis and tendon damage and proposed recently a tenosynovitis US scoring system [34,55-60].

Tenosynovitis was initially defined as hypoechoic or anechoic thickened tissue with or without fluid within the tendon sheath, which is seen in 2 perpendicular planes and which may exhibit a Doppler signal [55]. This definition has suffered some adjustments over time and remarks regarding the Doppler signal extension and differentiation from normal feeding vessels and also has included the definition of a normal tendon(Table I) [57].

Tendon damage was defined as an internal and/ or peripheral focal tendon defect (ie, absence of fibres) in the region enclosed by the tendon sheath, seen in two perpendicular planes [34].

A number of important studies dealt with construct validity where MSUS had different comparators such as CE, MRI, X-ray, or laboratory data.The presence of tenosynovitis was in generally correlated with the CE and inflammatory laboratory parameter. MSUS assessment detected more tendon pathology in comparison to clinical evaluation but was less sensitive in comparison to MRI.
Overall, MSUS showed a fair to moderate sensitivity but a high specificity $[28,29,31,33,37,46,60-72]$.

Regarding criterion validity, Swen et al studied concurrent validity of US in the detection of tendon tear in RA patients who were exposed to hand surgery due to the persistent tenosynovitis [63]. In a recent study, Janta et al used a surrogate model (cadaver), with previously prepared tendon damage,testing the MSUS detection of the tendon pathology in an inter-observer exercise [73].

The predictive validity of US tenosynovitis in relation to radiographic progression was reported by the group of Lillegraven $\mathrm{S}$ et al [74]. The study has demonstrated that MSUS-assessed tenosynovitis (ECU) predicts the development of erosive joint damage in a cohort of early RA patients [74]. Previously, the same group reported a predictive value of an overall ultrasonography score and a cross-sectional association between MSUS erosions and erosions assessed by MRI and conventional radiographs [75]. The predictive value of MSUS in detecting the RA patients in unstable remission was reported recently by Janta et al in a study comparing different reduced joint MSUS assessment of synovitis and tenosynovitis. No estimation regarding the impact of MSUS PD tenosynovitis could have been made in this group of patients since no patient in clinical remission presented PD tenosynovitis [76]. Similar results were found by Vlad et al in a recent study evaluating MSUS synovitis and tenosynovitis response to biologic therapy [77]. Both studies suggest that MSUS-assessed tenosynovitis may be closer to clinically assessed remission than MSUS- assessed synovitis in patients with RA.

Reliability for tendon abnormalities assessment was published in several recent studies focusing on interobserver/ intra-observer reliability, inter-observer- acquisition and inter- intra-observer reading reliability $[56,59,73,78]$.

\section{Tenosynovitis and other tendon abnormalities scoring systems}

A variety of scoring systems were developed in time for the tenosynovitis assessment - binary scoring sys-

Table I. Ultrasonographic definitions of normal tendon and related structures - adapted from [57].

\begin{tabular}{ll}
\hline & Definition \\
\hline Tendon & $\begin{array}{l}\text { Hyperechoic (relative to subdermal fat) fibrillar pattern (ie, hyperechoic parallel lines in longitudinal } \\
\text { planes and hyperechoic dots in transverse planes). }\end{array}$ \\
$\begin{array}{l}\text { Tendon synovial } \\
\text { sheath }\end{array}$ & $\begin{array}{l}\text { A thin regular hypoechoic (relative to tendon fibres) halo surrounding/ thin regular hypoechoic lines above } \\
\text { and below the tendon structure in transverse/longitudinal plane respectively at anatomical sites where } \\
\text { synovial sheaths are known to exist and which can be distinguished from pulleys and retinaculae. }\end{array}$ \\
$\begin{array}{l}\text { Retinaculae and } \\
\text { pulleys }\end{array}$ & $\begin{array}{l}\text { Focal hypoechoic (relative to tendon fibres) thickening of the peritendinous tendon sheath with fibrillar } \\
\text { pattern in the area located perpendicular to the probe, at its expected normal anatomical location. }\end{array}$ \\
\hline
\end{tabular}


tems, semi-quantitative grey scale or combined grey scale and Doppler and global inflammatory scores (synovitis and tenosynovitis) [25,26,65,69,77,79-83]. Recently, OMERACT proposed a new four -grade tenosynovitis scoring system along with a more detailed definition of the normal tendons and related structures, description of the elementary lesions of tenosynovitis on B-mode and Doppler mode and definition of tenosynovitis (table II, table III) [57]. This scoring system quantifies the Doppler signals within the widened synovial sheath and inside the tendon belly, excluding those in characteristic locations of the feeding blood supply.

Multicentric inter-observer reliability proved to be good for power Doppler (PD) evaluation, moderate for $\mathrm{B}$-mode assessment. Intra-observer agreement was good for B-mode as well as for PD assessment [84].

For the tendon damage a recent scoring system was elaborated by Bruyn et al [85]. The expert panel underlined the necessity to assess the tendon damage in both planes: transversal and longitudinal. They established a four-grade semi-quantitative scoring system (ie, grade 0 , normal; grade 1, minimal;grade 2, moderate; grade 3 , severe) in order to score the tendon damage using B mode US. Among experienced ultrasonographers, interobserver and intra-observer reliability was high, showing relevance for clinical practice [85].

\section{Responsiveness and feasibility of MSUS detected tenosynovitis.}

So far, MSUS detected tenosynovitis proved to be responsive to effective treatment in RA patients. Sensitivity to change was studied in a number of recent studies $[25,75,79-82,86,87]$. Feasibility of the method was tested in several papers $[25,28,59,80]$. Naredo et al performed an intra and inter-observer exercise with 35 examiners and concluded that intra-observer reliability for both GS and PD assessment was good ( $\mathrm{k}$ values 0.72 vs 0.78 ) and that inter-observer reliability was moderate for GS $(\mathrm{k}=0.47)$ and good for PD assessment $(\mathrm{k}=0.60)$ concluding that MSUS is a reproducible tool useful for the evaluation and monitoring tenosynovitis [25]. Boyesen et al demonstrated in a study performed on 53 patients that both high resolution imaging methods (MSUS and MRI) are independent predictors for further bone erosion development and that both methods were superior to other predictor parameters such as anti CCP antibodies, RF and DAS 28. MSUS for GS evaluation performed best [75]. Nareo et al performed a multicentric Spanish study on 279 patients evaluating PD articular and peri-articular activity testing the validity, responsiveness and predictive value of PDUS in monitoring response to TNF alpha blocking agents in RA. A significant parallel decrease of

Table II. ltrasonographic definitions of tendon sheath abnormalities - adapted from [57].

\begin{tabular}{|c|c|}
\hline & Definition \\
\hline $\begin{array}{l}\text { Tenosynovitis, } \\
\text { B-mode }\end{array}$ & $\begin{array}{l}\text { Abnormal anechoic and/or hypoechoic (relative to tendon fibres) tendon sheath widening which can be } \\
\text { related to both the presence of tenosynovial abnormal fluid and/or hypertrophy }\end{array}$ \\
\hline $\begin{array}{l}\text { Tenosynovitis, } \\
\text { Doppler mode }\end{array}$ & $\begin{array}{l}\text { Peritendinous Doppler signal within the synovial sheath, seen in two perpendicular planes, excluding } \\
\text { normal feeding vessels (ie, vessels at the mesotenon or vinculae or vessels entering the synovial sheath from } \\
\text { surrounding tissues) only if the tendon shows peritendinous synovial sheath widening on B-mode. }\end{array}$ \\
\hline $\begin{array}{l}\text { Tendon sheath ef- } \\
\text { fusion }\end{array}$ & $\begin{array}{l}\text { Presence of abnormal anechoic or hypoechoic (relative to tendon fibres) material within the synovial sheath, } \\
\text { either localised (eg, in the synovial sheath cul-de-sacs) or surrounding the tendon that is displaceable and } \\
\text { seen in two perpendicular planes. }\end{array}$ \\
\hline $\begin{array}{l}\text { Tenosynovial } \\
\text { hypertrophy }\end{array}$ & $\begin{array}{l}\text { Presence of abnormal hypoechoic (relative to tendon fibres) within the synovial sheath that is not displace- } \\
\text { able and poorly compressible and seen in two perpendicular planes }\end{array}$ \\
\hline
\end{tabular}

Table III. US scoring system for tenosynovitis on B-mode and Doppler mode- adapted from [57].

\begin{tabular}{lll}
\hline \multicolumn{2}{l}{ Tenosynovitis } & Doppler mode \\
\hline Grade & B mode & $\begin{array}{l}\text { No Doppler signal } \\
\text { Minimal: peritendinous focal signal within the widened synovial sheath (ie, signals in only one } \\
\text { area of the widened sheath), seen in two perpendicular planes, excluding normal feeding vessels } \\
\text { moderate peritendinous multifocal signal within the widened synovial sheath (ie, signals in more } \\
\text { than one area of the widened sheath), seen in two perpendicular planes, excluding normal feed- } \\
\text { ing vessels } \\
\text { severe, peritendinous diffuse signal within the widened synovial sheath (ie, signals filling most } \\
\text { of the widened sheath), in two perpendicular planes, excluding normal feeding vessels }\end{array}$ \\
Moderate & $\begin{array}{l}\text { Severe } \\
\text { If in addition to an abnormal intra-sheath signal there was an abnormal intratendinous signal seen in two perpendicular planes, } \\
\text { then grades 1 and 2 would be increased by one point }\end{array}$ \\
\hline
\end{tabular}


all clinical, functional and PDUS parameters was found at follow-ups. The authors found a high degree of intra and inter-observer reliability and a statistic significant sensitivity to change for PD assessment [80]. The same results regarding the sensitivity to change were obtained by Hammer et al in a study recruiting 20 patients when calculating the dynamic change of the sum scores in extensor carpi ulnaris and tibialis posterior tendons in patients with RA [81].

Backhaus et all evaluated in 120 patients the semiquantitative findings of PDUS activity (synovitis and tenosynovitis) and found a good inter and intra-reader agreement for both GS and PD assessment ( $\mathrm{k}$ values $0.62 \mathrm{vs}$ 0.84 ; $\mathrm{k}$ values 0.83 vs 0.64 ). For tenosynovitis, a $64.3 \%$ inter-reader agreement was found [82]. The same results were obtained by Bruyn et al in an exercise evaluating 9 patients (13 experts). An intra-observer agreement was 0.55 for GS inflammatory lesion detection versus 0.64 for PD evaluation. For tendon damage the intra-observer agreement $\mathrm{k}$ was 0.66 for PD and 0.53 for GS evaluation. Inter-observer evaluation showed substantial overall agreement $80-89 \%$ for GS assessment and $97-100 \%$ for PD assessment in both inflammatory and structural lesions detection [59].

\section{Conclusions}

MSUS is a promising imaging tool complementary to $\mathrm{CE}$ for evaluating and monitoring tendon abnormalities. The easy access to the ultrasound and the possibility to perform quickly, multiple anatomic areas assessment, and to repeat this assessment at any point during the disease course without exposing the patient to radiation or any other danger, represents the key to a successful "treat to target " strategy and to a better functional outcome.

\section{Conflict of interest: none}

\section{References}

1. Smolen JS, Aletaha D. Rheumatoid arthritis therapy reappraisal: strategies, opportunities and challenges. Nat Rev Rheumatol 2015; 11: 276-289.

2. Kavanaugh A, Fleischmann RM, Emery P, et al. Clinical, functional and radiographic consequences of achieving stable low disease activity and remission with adalimumab plus methotrexate or methotrexate alone in early rheumatoidarthritis: 26-week results from the randomised, controlled OPTIMA study. Ann Rheum Dis 2013; 72: 64-71.

3. Smolen JS, Aletaha D, Bijlsma JW, et al. Treating rheumatoid arthritis to target: recommendations of an international task force. Ann Rheum Dis 2010; 69: 631-637.
4. Radner H, Smolen JS, Aletaha D. Remission in rheumatoid arthritis: benefit over low disease activity in patient-reported outcomes and costs. Arthritis Res Ther 2014; 16: R56.

5. Felson DT, Smolen JS, Wells G, et al. American College of Rheumatology/European League against Rheumatism provisional definition of remission in rheumatoid arthritis for clinical trials. Ann Rheum Dis 2011; 70: 404-413.

6. Wakefield RJ, D'Agostino MA, Naredo E, et al. After treatto-target: can a targeted ultrasound initiative improve RA outcomes? Ann Rheum Dis 2012; 71: 799-803.

7. McAlindon T, Kissin E, Nazarian L, et al. American College of Rheumatology report on reasonable use of musculoskeletal ultrasonography in rheumatology clinical practice. Arthritis Care Res (Hoboken) 2012; 64: 1625-1640.

8. Klauser AS, Tagliafico A, Allen GM, et al. Clinical indications for musculoskeletal ultrasound: a Delphi-based consensus paper of the European Society of Musculoskeletal Radiology. Eur Radiol 2012; 22: 1140-1148.

9. Colebatch AN, Edwards CJ, Ostergaard M, et al. EULAR recommendations for the use of imaging of the joints in the clinical management of rheumatoid arthritis. Ann Rheum Dis 2013; 72: 804-814.

10. Cohen G, Gossec L, Dougados M, et al. Radiological damage in patients with rheumatoid arthritis on sustained remission. Ann Rheum Dis 2007; 66: 358-363.

11. Molenaar ET, Voskuyl AE, Dinant HJ, Bezemer PD, Boers M, Dijkmans BA. Progression of radiologic damage in patients with rheumatoid arthritis in clinical remission. Arthritis Rheum 2004; 50: 36-42.

12. Brown AK, Conaghan PG, Karim Z, et al. An explanation for the apparent dissociation between clinical remission and continued structural deterioration in rheumatoid arthritis. Arthritis Rheum 2008; 58: 2958-2967.

13. Mäkinen H, Kautiainen H, Hannonen P, et al. Sustained remission and reduced radiographic progression with combination disease modifying antirheumatic drugs in early rheumatoid arthritis. J Rheumatol 2007; 34: 316-321.

14. Brown AK, Quinn MA, Karim Z, et al. Presence of significant synovitis in rheumatoid arthritis patients with disease modifying antirheumatic drug-induced clinical remission: evidence from an imaging study may explain structural progression. Arthritis Rheum 2006; 54: 3761-3773.

15. Conaghan PG, O'Connor P, McGonagle D, et al. Elucidation of the relationship between synovitis and bone damage: a randomized magnetic resonance imaging study of individual joints in patients with early rheumatoid arthritis. Arthritis Rheum 2003; 48: 64-71.

16. Naredo E, Collado P, Cruz A, et al. Longitudinal power Doppler ultrasonographic assessment of joint inflammatory activity in early rheumatoid arthritis: predictive value in disease activity and radiologic progression. Arthritis Rheum 2007; 57: 116-124.

17. Micu MC, Fodor D. Concepts in monitoring the treatment in rheumatoid arthritis - the role of musculoskeletal ultrasound. Part I: synovitis. Med Ultrason 2015; 17: 367-376.

18. Newman JS, Laing TJ, McCarthy CJ, Adler RS. Power Doppler sonography of synovitis: assessment of therapeutic 
response-preliminary observations. Radiology 1996; 198: 582-584.

19. Hau M, Kneitz C, Tony HP, Keberle M, Jahns R, Jenett M. High resolution ultrasound detects a decrease in pannus vascularisation of small finger joints in patients with rheumatoid arthritis receiving treatment with soluble tumour necrosis factor alpha receptor (etanercept). Ann Rheum Dis 2002; 61: 55-58.

20. Schmidt WA, Volker L, Zacher J, Schlafke M, Ruhnke M, Gromnica-Ihle E. Colour Doppler ultrasonography to detect pannus in knee joint synovitis. Clin Exp Rheumatol 2000; 18: 439-444.

21. Walther M, Harms H, Krenn V, Radke S, Faehndrich TP, Gohlke F. Correlation of power Doppler sonography with vascularity of the synovial tissue of the knee joint in patients with osteoarthritis and rheumatoid arthritis. Arthritis Rheum 2001; 44: 331-338.

22. Giovagnorio F, Martinoli C, Coari G. Power Doppler sonography in knee arthritis-a pilot study. Rheumatol Int 2001; 20: 101-104.

23. Porta F, Radunovic G, Vlad V, et al. The role of Doppler ultrasound in rheumatic diseases. Rheumatology 2012; 51: 976-982.

24. Filippucci E, Iagnocco A, Salaffi F, Cerioni A, Valesini G, Grassi W. Power Doppler sonography monitoring of synovial perfusion at the wrist joints in patients with rheumatoid arthritis treated with adalimumab. Ann Rheum Dis 2006; 65: 1433-1437.

25. Naredo E, Rodriguez M, Campos C, et al. Validity, reproducibility, and responsiveness of a twelve-joint simplified power Doppler ultrasonographic assessment of joint inflammation in rheumatoid arthritis. Arthritis Rheum 2008; 4: $515-522$.

26. Iagnocco A, Finucci A, Ceccarelli F, Perricone C, Iorgoveanu V, Valesini G. Power Doppler ultrasound monitoring of response to anti-tumor necrosis factor alpha treatment in patients with rheumatoid arthritis. Rheumatology 2015; 54: 1890-1896.

27. Dale J, Purves D, McConnachie A, McInnes I, Porter D. Tightening up? Impact of musculoskeletal ultrasound disease activity assessment on early rheumatoid arthritis patients treated using a treat to target strategy. Arthritis Care Res (Hoboken) 2014; 66: 19-26.

28. Grassi W, Tittarelli E, Blasetti P, Pirani O, Cervini C. Finger tendon involvement in rheumatoid arthritis. Evaluation with high frequency sonography. Arthritis Rheum 1995; 38: 786-794.

29. Wakefield RJ, O'Connor PJ, Conaghan PG, McGonagle D, Hensor EM, Gibbon WW, Brown C, Emery P: Finger tendon disease in untreated early rheumatoid arthritis: a comparison of ultrasound and magnetic resonance imaging. Arthritis Rheum 2007; 57: 1158-1164.

30. Hmamouchi I, Bahiri R, Srifi N, Aktaou S, Abouqual R, Hajjaj-Hassouni N. A comparison of ultrasound and clinical examination in the detection of flexor tenosynovitis in early arthritis. BMC Musculoskelet Disord 2011; 12: 91 .
31. Navalho M, Resende C, Rodrigues AM, et al. Bilateral evaluation of the hand and wrist in untreated early inflammatory arthritis: a comparative study of ultrasonography and magnetic resonance imaging. J Rheumatol 2013; 40; 1282-1292.

32. Navalho M, Resende C, Rodrigues AM, et al. Bilateral MR imaging of the hand and wrist in early and very early inflammatory arthritis: tenosynovitis is associated with progression to rheumatoid arthritis. Radiology 2012; 264: 823-833.

33. Janta I, Stanciu D, Hinojosa M, et al. Structural damage in rheumatoid arthritis: comparison between tendon damage evaluated by ultrasound and radiographic damage. Rheumatology 2016; 55: 1042-1046.

34. Bruyn GA, Hanova P, Iagnocco A, et al; OMERACT Ultrasound Task Force. Ultrasound definition of tendon damage in patients with rheumatoid arthritis. Results of a OMERACT consensus-based ultrasound score focusing on the diagnostic reliability. Ann Rheum Dis 2014; 73: 1929-1934.

35. Jacobs JH, Hess EV, Beswick IP. Rheumatoid arthritis presenting as tenosynovitis. J Bone Joint Surg Br 1957; 39-B: 288-292.

36. Cader MZ, Filer A, Hazlehurst J, de Pablo P, Buckley CD, Raza K. Performance of the 2010 ACR/EULAR criteria for rheumatoid arthritis: comparison with 1987 ACR criteria in a very early synovitis cohort. Ann Rheum Dis 2011; 70: 949-955.

37. McQueen F, Beckley V, Crabbe J, et al. Magnetic Resonance Imaging Evidence of Tendinopathy in Early Rheumatoid Arthritis Predicts Tendon Rupture at Six Years. Arthritis\& Rheumatism 2005; 52: 744-751.

38. Lindegaard HM, Vallø J, Hørslev-Petersen K, Junker P, Østergaard M. Low-cost, low-field dedicated extremity magnetic resonance imaging in early rheumatoid arthritis: a 1-year follow-up study. Ann Rheum Dis 2006; 65: 1208-1212.

39. Eshed I, Feist E, Althoff CE, et al. Tenosynovitis of the flexor tendons of the hand detected by MRI: an early indicator of rheumatoid arthritis. Rheumatology 2009; 48: 887-891.

40. Backhaus M, Burmester GR, Sandrock D, et al. Prospective two year follow up study comparing novel and conventional imaging procedures in patients with arthritic finger joints. Ann Rheum Dis 2001; 61: 895-904.

41. Wakefield RJ, Green MJ, Marzo-Ortega H, et al. Should oligoarthritis be reclassified? Ultrasound reveals a high prevalence of subclinical disease. Ann Rheum Dis 2004; 63: 382-385

42. Naredo E, Bonilla G, Gamero F,e t al. Assessment of inflammatory activity in rheumatoid arthritis:a comparative study of clinical evaluation with grey scale and power Doppler ultrasonography. Ann Rheum Dis 2005; 64: 375-381.

43. Koski JM. Detection of plantar tenosynovitis of the forefoot by ultrasound in patients with early arthritis. Scand J Rheumatol1995; 24: 312-313.

44. Filippucci E, Gabba A, Di Geso L, Girolimetti R, Salaffi F, Grassi W. Hand tendon involvement in rheumatoid arthritis: an ultrasound study. Semin Arthritis Rheum 2011; 41: 752-760. 
45. Grassi W, Filippucci E, Farina A, Cervini C. Sonographic imaging of tendons. Arthritis Rheum 2000; 43: 969-976.

46. Klauser AS, Franz M, Arora R, et al. Detection of vascularity in wrist tenosynovitis: power doppler ultrasound compared with contrast-enhanced grey-scale ultrasound. Arthritis Res Ther 2010; 12: R209.

47. Ammitzboll-Danielsen M, Janta I, Torp- Pedersen S, Naredo E, Ostergaard M. Three-dimensional Doppler ultrasound findings in healthy wrist and finger tendon sheaths- can feeding vessels lead to misinterpretation in Doppler- detected tenosynovitis? Arthritis Res Ther 2016; 18: 70.

48. Terslev L, Torp-Pedersen S, Qvistgaard E, von der Recke P, Bliddal H. Doppler ultrasound findings in healthy wrists and finger joints. Ann Rheum Dis 2004; 63: 644-648.

49. Carotti M, Salaffi F, Morbiducci J, Ciapetti A, Bartolucci L, Gasparini S, et al. Colour Doppler ultrasonography evaluation of vascularization in the wrist and finger joints in rheumatoid arthritis patients and healthy subjects. Eur J Radiol 2012; 81: 1834-1838.

50. Millot F, Clavel G, Etchepare F, Gandjbakhch F, Grados F, Saraux A, et al. Musculoskeletal ultrasonography in healthy subjects and ultrasound criteria for early arthritis (the ESPOIR cohort). J Rheumatol 2011; 38: 613-620.

51. Morel M, Boutry N, Demondion X, Legroux-Gerot I, Cotten H, Cotten A. Normal anatomy of the heel entheses: anatomical and ultrasonographic study of their blood supply. Surg Radiol Anat 2005; 27: 176-183.

52. Torp-Pedersen ST, Terslev L. Settings and artefacts relevant in colour/power Doppler ultrasound in rheumatology. Ann Rheum Dis 2008; 67: 143-149.

53. Filippucci E, Meenagh G, DelleSedie A, et al. Ultrasound imaging for the rheumatologist. XX. Sonographic assessment of hand and wrist joint involvement in rheumatoid arthritis: comparison between two- and three-dimensional ultrasonography. Clin Exp Rheumatol 2009; 27: 197-200.

54. Torp-Pedersen S, Christensen R, Szkudlarek M, et al. Power and color Doppler ultrasound settings for inflammatory flow: impact on scoring of disease activity in patients with rheumatoid arthritis. Arthritis Rheumatol 2015; 67: 386395.

55. Wakefield RJ, Balint P, Szkudlarek M, Flippucci E, Backhaus M, D'Agostino MA, et al. Musculoskeletal ultrasound including definitions for ultrasonographic pathology. J Rheumatol 2005; 32: 2485-2487.

56. Alcalde M, D'Agostino MA, Bruyn G, et al. A systematic literature review of US definitions, scoring systems and validity according to the OMERACT filter for tendon lesion in RA and other inflammatory joint diseases. Rheumatology 2012; 51: 1246-1260.

57. Naredo E, d'Agostino MA, Wakefield RJ, et al; OMERACT Ultrasound Task Force. Reliability of a consensus based ultrasound score for tenosynovitis in rheumatoid arthritis. Ann Rheum Dis 2013; 72: 1328-1334.

58. Micu MC, Serra S, Fodor D, Crespo M, Naredo E. Interobserver reliability of ultrasound detection of tendon abnormalities at the wrist and ankle in patients with rheumatoid arthritis. Rheumatology 2011; 50: 1120-1124.
59. Bruyn GA, Moller I, Garrido J, et al. Reliability testing of tendon disease using two different methods in patients with rheumatoid arthritis. Rheumatology 2012; 51: 1655-1661.

60. Fornage BD. Soft-tissue changes in the hand in rheumatoid arthritis: evaluation with US. Radiology 1989; 173: 735737.

61. Coakley FV, Samanta AK, Finlay DB. Ultrasonography of the tibialis posterior tendon in rheumatoid arthritis. $\mathrm{Br} \mathrm{J}$ Rheumatol 1994; 33: 273-277.

62. Lehtinen A, Paimela L, Kreula J, et al. Painful ankle region in rheumatoid arthritis. Analysis of soft-tissue changes with ultrasonography and MR imaging. Acta Radiol 1996; 37: 572-577.

63. Swen WA, Jacobs JW, Hubach PC, et al. Comparison of sonography and magnetic resonance imaging for the diagnosis of partial tears of finger extensor tendons in rheumatoid arthritis. Rheumatology 2000; 39: 55-62.

64. Premkumar A, Perry MB, Dwyer AJ, et al. Sonography and MR imaging of posterior tibial tendinopathy. AJR Am J Roentgen 2002; 178: 223-232.

65. Hoving JL, Buchbinder R, Hall S, et al. A comparison of magnetic resonance imaging, sonography, and radiography of the hand in patients with early rheumatoid arthritis. J Rheumatol 2004; 31: 663-675.

66. Wiell C, Szkudlarek M, Hasselquist M et al. Ultrasonography, magnetic resonance imaging, radiography, and clinical assessment of inflammatory and destructive changes in fingers and toes of patients with psoriatic arthritis. Arthritis Res Ther 2007; 9: R119.

67. Baan H, Drossaers-Bakkers WK, Dubbeldam R, et al. Flexor hallucis longus tendon rupture in RA-patients is associated with MTP 1 damage and pes planus. BMC Musculoskelet Disord 2007; 8: 110.

68. Wakefield RJ, Freeston JE, O'Connor P, et al. The optimal assessment of the rheumatoid arthritis hindfoot: a comparative study of clinical examination, ultrasound and high field MRI. Ann Rheum Dis 2008; 67: 1678-1682.

69. Haavardsholm EA, Ostergaard M, Hammer HB, et al. Monitoring anti-TNFa treatment in rheumatoid arthritis: responsiveness of magnetic resonance imaging and ultrasonography of the dominant wrist joint compared with conventional measures of disease activity and structural damage. Ann Rheum Dis 2009; 68: 1572-1579.

70. Suzuki T, Tohda E, Ishihara K. Power Doppler ultrasonography of symptomatic rheumatoid arthritis ankles revealed a positive association between tenosynovitis and rheumatoid factor. Mod Rheumatol 2009; 19: 235-244.

71. Suzuki T. Ultrasound detected tenosynovitis in ankles of early RA patients. Clin Exp Rheumatol 2013; 31: 281-284.

72. Suzuki T, Okamoto A. Ultrasound examination of symptomatic ankles in shorter-duration rheumatoid arthritis patients often reveals tenosynovitis. Clin Exp Rheumatol 2013; 31: 281-284.

73. Janta I, Moran J, Naredo E, et al. How does a cadaver model work for testing ultrasound diagnostic capability for rheumatic-like tendon damage? Rheumatology International 2016; 36: 863-869. 
74. Lillegraven S, Bøyesen P, Hammer HB, et al. Tenosynovitis of the extensor carpi ulnaris tendon predicts erosive progression in early rheumatoid arthritis. Ann Rheum Dis November 2011; 70: 2049-2050.

75. BøyesenP ,Haavardsholm EA, van der Heijde D, et al. Prediction of MRI erosive progression: a comparison of modern imaging modalities in early rheumatoid arthritis patients. Ann Rheum Dis 2011; 70: 176-179 .

76. Janta I, Valor L, De la Torre I, et al. Ultrasound -detected activity in rheumatoid arthritis on methotrexate therapy: Which joints and tendons should be assessed to predict unstable remission? Rheumatol Int 2016; 36: 387-396.

77. Vlad V, Berghea F, Micu M, et al. Tenosynovitis US scoring systems follow synovitis and clinical scoring systems in RA and are responsive to change after biologic therapy. Med Ultrason 2015; 17: 352-360.

78. Naredo E, Moller I, Acebes C, et al. Three-dimensional volumetric ultrasonography. Does it improve reliabililty of musculoskeletal ultrasound? Clin Exp Rheumatol 2010; 28: 79-82.

79. Iagnocco A, Perella C, Naredo E et al. Etanercept in the treatment of rheumatoid arthritis: clinical follow-up over 1 year by ultrasonography. Clin Rheumatol 2008; 27: 491496.

80. Naredo E, Moller I, Cruz A, et al. Power Doppler ultrasound monitoring of response to anti-tumor necrosis factor therapy in patients with rheumatoid arthritis. Arthritis Rheum 2008; 58: 2248-2256.
81. Hammer HB, Kvien TK. Ultrasonography shows significantimprovement in wrist and ankle tenosynovitis in rheumatoidarthritis patients treated with adalimumab. Scand J Rheumatol 2011; 40: 178-182.

82. Backhaus M, Ohrndorf S, Kellner H, et al. Evaluation of a novel 7-joint ultrasound score in daily rheumatologic practice: a pilot project. Arthritis Rheum 2009; 61: 1194-201.

83. Lehtinen A, Paimela L, Kreula J, et al. Painful ankle region in rheumatoid arthritis. Analysis of soft-tissue changes with ultrasonography and MR imaging. Acta Radiol 1996; 37 : 572-527.

84. Naredo E, D'Agostino MA, Wakefield RJ, et al. Reliability of a consensus-based ultrasound score for tenosynovitis in rheumatoid arthritis. Ann Rheum Dis 2013; 72: 1328-1334.

85. Bruyn GAW, Hanova P, Iagnocco A, et al. Ultrasound definition of tendon damage in patients with rheumatoid arthritis. Results of a OMERACT consensus-based ultrasound score focusing on the diagnostic reliability. Ann Rheum Dis 2014; 73: 1929-1934.

86. Iagnocco A, Filippucci E, Perella C, et al. Clinical and ultrasonographic monitoring of response to Adalimumab treatment in rheumatoid arthritis. J Rheumatol 2008; 35: 35-40.

87. Terslev L, Torp-Pedersen S, Qvistgaard E, et al. Effects of treatment with etanercept (Enbrel, TNRF:Fc) on rheumatoid arthritis evaluated by Doppler ultrasonography. Ann Rheum Dis 2003; 62: 178-181. 